\title{
Effectiveness of a Uniquely Designed Oral Appliance on Obstructive Sleep Apnea Control: A Pilot Study
}

\author{
Denise Fernandes Barbosa1 ${ }^{10}$ Miguel Meira e Cruz 2,3 [1] \\ Fausto Berzin ${ }^{5}$ Almiro José Machado Júnior ${ }^{10}$ \\ ${ }^{1}$ Division of Surgical Sciences, Department of Otorhinolaryngology, \\ School of Medical Sciences, University of Campinas, UNICAMP, São \\ Paulo, Brazil \\ 2 Sleep Unit, Centro Cardiovascular da Universidade de Lisboa, Lisbon \\ School of Medicine, Lisbon, Portugal \\ ${ }^{3}$ Research Laboratory on the Neuroimmune Interface of Pain São \\ Leopoldo Mandic College, Campinas, São Paulo, Brazil \\ ${ }^{4}$ ESALQ, University of Sao Paolo, Piracicaba, São Paulo, Brazil \\ ${ }^{5}$ Department of Odontology, FOP - UNICAMP, Piracicaba, São Paulo, \\ Brazil
}

Eur J Dent 2022;16:564-572.

\author{
Marcelo Corrêa Alves ${ }^{4(1)}$ Edilson Zancanella10
}

Address for correspondence Almiro José Machado Júnior, PhD, Division of Surgical Sciences, Department of Otorhinolaryngology, Medical Sciences College, University of Campinas, UNICAMP, R. Tessália Vieira de Camargo, 126 - Cidade Universitária, Campinas, Sao Paolo 13083-887, Brazil (e-mail: almiromachadophd@gmail.com).

\begin{abstract}
Keywords

- obstructive sleep apnea syndrome

- oral appliance therapy

- upper airway
\end{abstract}

Objectives Obstructive sleep apnea is an inflammatory, chronic, and evolutive disease often needing adequate treatment and follow-up. The oral appliance (OA) is an accepted alternative therapy for obstructive sleep apnea (OSA) control. Due to greater adherence, $\mathrm{OA}$ with mandibular advancement $\left(\mathrm{OA}_{\mathrm{m}}\right)$ is being recommended treatment for patients who refuse or do not tolerate continuous positive airway pressure. The mode of action of $\mathrm{OA}_{\mathrm{m}}$ is to promote the advancement of the mandible or tongue with a subsequent increase in the tone of the pharyngeal muscles and the permeability of the upper airway, but most $\mathrm{OA}_{\mathrm{m}}$ use conventional models as reference, analogic, or digital, dissociating dental arches of the skull structures.

Materials and Methods A retrospective longitudinal study of 33 OSA patient treated with a different $O A_{m}$, that use Camper plane as reference with skull structures for dental arches disocclusion, where polysomnographic, cephalometric measures, and subjective data from questionnaires pre- and post-treatment were assessed and correlated. Descriptive analysis, correlated Chi-square tests, and basic statistics were used. Generalized linear mixed model for repeated measure and post hoc TukeyKramer test compares the variables pre- and post-treatment. Shapiro-Wilk test and Pearson's correlation coefficients were used. All statistical tests were set in $5 \%$ level of significance.

Results Regarding polysomnography data, there was a significant association between apnea hypopnea index ( $\mathrm{AHI}$ ) with oxygen saturation, arousal index (AI) and the maximum heartbeats, and sleep improvement and health risk reduction. Additionally, from cephalometric data, it was found a significant association between the tongue posture with the soft palate, hioyd-C3 and, lower and posterior airway. When both published online

February 18, 2022
DOI https://doi.org/

10.1055/s-0041-1735933.

ISSN 1305-7456.

\section{(c) 2022. The Author(s).}

This is an open access article published by Thieme under the terms of the Creative Commons Attribution License, permitting unrestricted use, distribution, and reproduction so long as the original work is properly cited. (https://creativecommons.org/licenses/by/4.0/)

Thieme Medical and Scientific Publishers Pvt. Ltd., A-12, 2nd Floor, Sector 2, Noida-201301 UP, India 
parameters are correlated, there are a significant dependent association with hyoid bone position with $\mathrm{AHI}$ and $\mathrm{Al}$. The limitation of this study was the two-dimensional image used without provide volumetric measurements, but this limitation was reduced with the follow-up polysomnography parameters.

Conclusion In this pilot study, DIORS $\mathrm{OA}_{\mathrm{m}}$ as an uniquely designed device using Camper plane as a reference for disocclusion was effective in the control of OSA.

\section{Introduction}

Obstructive sleep apnea (OSA) is a chronic, inflammatory, and progressive disease. ${ }^{1,2}$ Its prevalence in the general population is between 9 and 38\%, and varies according to age and gender. $^{3}$ The diagnosis ${ }^{4}$ requires either signs/symptoms (e.g., associated sleepiness, fatigue, insomnia, snoring, subjective nocturnal respiratory disturbance, or observed apnea) or associated medical or psychiatric disorder (i.e., hypertension, coronary artery disease, atrial fibrillation, congestive heart failure, stroke, diabetes, cognitive dysfunction, or mood disorder) coupled with five or more predominantly obstructive respiratory events (obstructive and mixed apneas, hypopneas, or respiratory effort-related arousals, as defined by the American Academy of Sleep Medicine scoring manual) per hour of sleep during polysomnography (PSG). Alternatively, a frequency of obstructive respiratory events $15 /$ hour satisfies the criteria, even in the absence of associated symptoms or disorders.

Clinical symptoms vary depending on the type, frequency, and intensity of the respiratory abnormality. ${ }^{5,6}$ Normal rates of apnea should also be treated when associated with snoring, although some controversial issues persist regarding the therapeutic criteria for snoring itself. ${ }^{7}$

The most recommended devices for usage by American Academy of Sleep Medicine and the American Academy of Dental Sleep Medicine ${ }^{8}$ are the oral appliance with mandibular advancement $\left(\mathrm{OA}_{\mathrm{m}}\right)$ for the treatment of primary snoring, mild and moderate obstructive sleep apnea (OSA), and the continuous positive airway pressure (CPAP) to moderate to severe OSA. In addition, $\mathrm{OA}_{\mathrm{m}}$ can be considered after CPAP has been failed in nonadherent patients treatment or in patient preference in therapy choosing. ${ }^{9,10}$

The new generation of $\mathrm{OA}_{\mathrm{m}}$ devices presents considerable advances in design, construction techniques, and individualization capacity. Considering the assumptions of design, construction, and individualization, $\mathrm{OA}_{\mathrm{m}}$ can further impact the effectiveness of oral appliance therapy (OAT) ${ }^{8}$

One of the problems related to respiratory disorders is the maxillomandibular relationship, both vertically, sagittal and transversal, ${ }^{11}$ significant differences existed in the craniofacial morphology of patients with OSA and the healthy population. In addition to this relationship, which is so important, most malocclusions are treated based on a conventional analog or digital model, ${ }^{12}$ which does not faithfully reproduce their interrelationships with cranial structures. These therapeutic proceed can bring important repercus- sions in the lives of these patients for not considering the intimate interrelationship of the dental arches with the craniofacial structures. ${ }^{13}$ Likewise, most $\mathrm{OA}_{\mathrm{m}}$ are structured, using models dissociated from their relationship with craniometric structures and, consequently, with the muscles involved in mandibular protrusion movements.

The functional anatomic factors leading to oropharynx and hypopharynx airway collapse in OSA, ${ }^{14,15}$ are in part related to the retracted position of the mandible and tongue with sagging soft palate. The principal mechanism of action of $\mathrm{OA}_{\mathrm{m}}$ is by promoting the advancement of the mandible or tongue ${ }^{14,16}$ because simple active anterior movement of the tongue or mandible can increase cross sectional airway size in subjects with and without OSA ${ }^{17,18}$ and, increasing the pharynx muscles tone and therefore the airway patency. Ideally, these situations could be achieved in the $\mathrm{OA}_{\mathrm{m}}$ mode of action simultaneously. ${ }^{14,19-22}$

One of the first functional mandibular activator devices was developed in Europe in the early 20th century which became a universal device widely used, thanks to Viggo Andresen. The removable activator devices were built to redirect the pressure of facial muscles and masticatory onto teeth and support structures to improve dental arrangement and occlusal relationships. This author used the Camper plane for diagnosis and follow-up. The Camper plane is a plane established by superior border of the tragus left and right to the lowest point of ala border. ${ }^{23}$

In OAT, the neuromuscular system will be activated through $\mathrm{OA}_{\mathrm{m}}$ maintaining upper airway patency, toning the oropharynx muscles, thus preventing collapse between the tissues of the oropharynx and tongue base, ${ }^{24}$ and improving tongue posture. ${ }^{25}$ The $\mathrm{OA}_{\mathrm{m}}$ cannot exceed anatomical physiological limits. Therefore, the choice of $\mathrm{OA}_{\mathrm{m}}$ for the treatment of OSA should be considered by Dental Sleep Medicine. ${ }^{21,24,26-28}$

In searching for functional balance, the DIORS $\mathrm{OA}_{\mathrm{m}}$ de$\operatorname{sign}^{29}$ considered these two situations because it was designed based on functional anatomy of buco-dental biology. The $\mathrm{OA}_{\mathrm{m}}$ disocclusion is guided to Camper plane based on fixed individual skull structures. At same time, it stimulates the tongue for advancement, promoting lip sealing which further improve the airway patency.

In Dental Sleep Medicine clinical practice, ${ }^{8}$ there are diagnostic and complementary exams with objective and subjective parameters need for records as polysomnography exam for diagnosing OSA, intra- and extraoral photographic examination to assess facial patterns, oral conditions, and 
follow-up cephalometric analyze of the airway space, which makes it possible to check the mandible and tongue position in relation bone structures ${ }^{14,30-33}$ and models of the dental arches for recording and making the $\mathrm{OA}_{\mathrm{m}}$. In addition to these objective parameters, the Epworth sleepiness scale is a subjective parameter, of proven validity, used for the evaluation and monitoring of the patient after treatment. ${ }^{8}$

Thus, the aim of this pilot study is to compare the impact of $\mathrm{OA}_{\mathrm{m}}$ that use Camper plane for reference to disocclusion, on the upper airways in snore and OSA patients, in the pre- and post-treatment in a private dental office through cephalometric analysis, and the effectiveness of this different $\mathrm{OA}_{\mathrm{m}}$ through polysomnographic parameters. Also, verify if there is a correlation with these variables associated with clinical practice.

\section{Materials and Methods}

\section{Study Design}

A retrospective longitudinal study was developed from dental sleep medical records of OSA patients treated with DIORS OA $\mathrm{m}_{\mathrm{m}}$, manufactured by the first author in her dental office, Jundiaí, SP, Brazil. The results were measuring and comparing by objective (polysomnography and cephalometric data) and subjective (Epworth sleepiness scale and adherence, symptoms, satisfaction, and safety questionnaires) data pre- and post-treatment. The data analysis was conducted by applying quantitative techniques and multiple comparisons (-Fig. 1).

The study was approved by the School of Odontology of Piracicaba UNICAMP Ethics Committee, SP, Brazil (CAAE: 20672219.3.0000.5418 P.N. /4.034.661). This study counted patients attending in private dental office with authorized and formalize participation with the informed consent.

\section{Sample}

In view of the nature of the variables to be analyzed, a sample size calculation was made based on the application of the Student $t$-test for paired data where the mean referring of null hypothesis was 0 ; the significant average, of two different units; the standard deviation of 4 ; and the desired power, $80 \%$, resulting in a total sample of 34 patients.

The inclusion criteria were both genders adult patients with snoring and mild, moderate and severe OSA prescribed by Sleep Physician treated with DIORS OA $\mathrm{m}$ in the first author dental office from 2011 to 2019 period, with completed medical records and protocol of 2 to 3 months of $\mathrm{OA}_{\mathrm{m}}$ adjustment. The records needed to have Epworth sleepiness scale, polysomnography and cephalometry pre- and posttreatment. The exclusion criteria were incomplete dental sleep medical records and patients that not permitted used the data for research.

The success criteria established in this study regarding elimination or decreasing of AHI symptoms ${ }^{17,29}$ were (1) successful (AHI < 5/hour); (2), partly successful (at least $50 \%$ reduction in $\mathrm{AHI}$, but $\mathrm{AHI}>5$ /hour; and (3) failure (persisting clinical symptoms, and/or less than $50 \%$ reduction in baseline AHI).

In - Table 1, the characteristics of 33 adults with anthropometrics and polysomnographic and cephalometric data

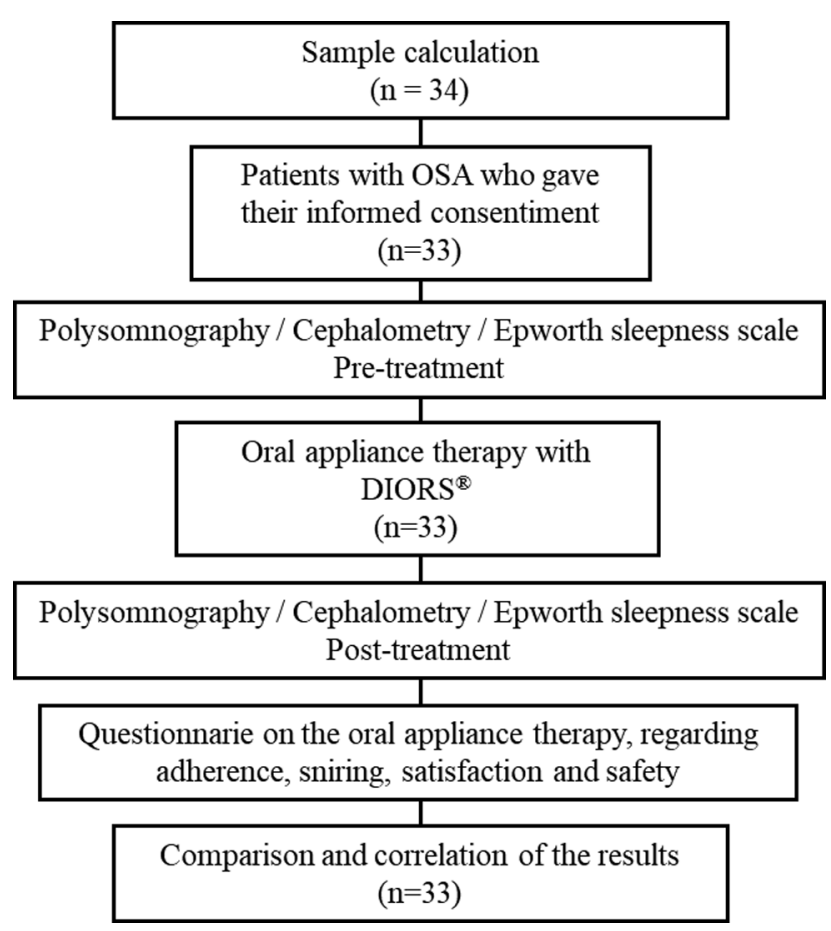

Fig. 1 Diagram of study development.

are showed. The anthropometric data consist in 25 men and 8 women pre- and post-treatment with mean (standard deviation) of 50.53 (10.29) years old and body mass index (BMI) of 27.70 (3.27). The angle occlusal classification of these sample is $86.96 \%$ of Class I and $13.04 \%$ of Class II. The AHI variation was 11.92 (12.80). Based on OSA severity, the sample consisted in simple snoring or normal apnea (AHI $<5)$ in $2.17 \%$, mild $(5 \leq \mathrm{AHI}<15)$ in $26.09 \%$, moderate $(15 \leq$ $\mathrm{AHI}<30)$ in $13.04 \%$, and severe $(\mathrm{AHI} \geq 30)$ in $8.7 \%$.

\section{Polysomnography}

Each subject underwent polysomnography all-night recordings in the sleep laboratory in two phases pre- and posttreatment. The polysomnographic study used was Brain Wave II Polysomnography (Neurovirtual, Barueri SP/Brazil) performed by physicians specially trained in sleep medicine. The AHI was defined as the number of episodes of apnea plus episodes of hypopnea per hour of sleep. OSA was defined as $\mathrm{AHI} \geq 5$.

\section{Cephalometry}

Cephalometric parameters were taken for the location of obstruction sites and to clarifying specific parameters to the upper airway with the software Radio Memory Studio 3.0 Release 7.80 (Radio Memory LTDA, Belo Horizonte MG/Brazil). Several analysis has been widely described in literature. ${ }^{14,30-33}$ The cephalometric analysis of airway space used and covered in two phases: without and with $\mathrm{OA}_{\mathrm{m}}$ preand post-treatment. The majority teleradiographs and cephalometric analysis (91.3\%) was performed by a single evaluator of Speed $\mathrm{X}$ Dental Documentation Center with Instrumentarium OC 200 Xray (KaVo company, Finland). 
Oral Appliance in Obstructive Sleep Apnea Therapy Barbosa et al. 567

Table 1 Mean, standard deviation, and confidence limits of the mean (95\%) that characterize sample data $(n=33)$

\begin{tabular}{|c|c|c|c|c|c|c|}
\hline \multirow[t]{2}{*}{ Characteristics } & \multirow[t]{2}{*}{ Mean } & \multirow[t]{2}{*}{ Standard deviation } & \multicolumn{2}{|c|}{$\begin{array}{l}95 \% \text { confidence } \\
\text { limit }\end{array}$} & \multirow[t]{2}{*}{ Minimum } & \multirow[t]{2}{*}{ Maximum } \\
\hline & & & Upper & Lower & & \\
\hline \multicolumn{7}{|l|}{ Anthropometric data } \\
\hline Cervical waist & 40.76 & 4.59 & 42.44 & 39.07 & 33.50 & 55.00 \\
\hline Abdominal waist & 98.98 & 10.21 & 102.73 & 95.24 & 74.00 & 117.00 \\
\hline Age & 50.53 & 10.29 & 54.18 & 46.88 & 29.54 & 70.92 \\
\hline Weight (kg) & 83.65 & 14.54 & 87.31 & 79.99 & 58.00 & 115.00 \\
\hline BMI $\left(\mathrm{kg} / \mathrm{m}^{2}\right)$ & 27.70 & 3.27 & 28.53 & 26.88 & 20.05 & 37.10 \\
\hline \multicolumn{7}{|l|}{ Polysomnographic data } \\
\hline Epworth sleepiness scale & 8.22 & 4.53 & 9.36 & 7.08 & 1.00 & 20.00 \\
\hline Arousal index & 9.05 & 8.90 & 11.29 & 6.81 & 0.40 & 53.13 \\
\hline $\mathrm{SaO}_{2}$ minimum (\%) & 85.57 & 5.65 & 86.99 & 84.15 & 64.00 & 93.00 \\
\hline Sleep efficiency & 76.83 & 12.38 & 79.95 & 73.72 & 45.60 & 96.00 \\
\hline Apnea & 4.89 & 8.56 & 7.05 & 2.74 & 0.00 & 43.40 \\
\hline Hypopnea & 7.02 & 6.78 & 8.73 & 5.32 & 0.00 & 33.72 \\
\hline $\mathrm{AHI}$ & 11.92 & 12.80 & 15.14 & 8.70 & 0.20 & 64.18 \\
\hline Minimum heartbeat & 54.71 & 7.60 & 56.71 & 52.71 & 44.00 & 78.00 \\
\hline Maximum heartbeat & 78.06 & 13.20 & 81.53 & 74.59 & 57.00 & 137.00 \\
\hline Legs movements & 3.29 & 7.83 & 5.30 & 1.29 & 0.00 & 36.20 \\
\hline \multicolumn{7}{|l|}{ Cephalometric data } \\
\hline Upper pharyngeal space & 17.74 & 4.14 & 18.76 & 16.72 & 9.83 & 27.07 \\
\hline Soft palate length & 41.90 & 5.88 & 43.34 & 40.45 & 28.23 & 58.57 \\
\hline Posterior air space & 13.85 & 4.20 & 14.88 & 12.82 & 6.05 & 25.61 \\
\hline Hyoid distance mandibular plane & 22.89 & 7.54 & 24.75 & 21.04 & 10.31 & 41.39 \\
\hline Tongue length & 78.84 & 9.27 & 81.12 & 76.56 & 57.46 & 97.30 \\
\hline Tongue height & 29.30 & 5.46 & 30.64 & 27.95 & 14.47 & 44.75 \\
\hline Lower air space & 12.79 & 4.65 & 13.94 & 11.65 & 5.14 & 24.69 \\
\hline Hyoid distance third cervical vertebrae & 42.81 & 5.42 & 44.15 & 41.48 & 32.40 & 53.32 \\
\hline
\end{tabular}

Abbreviations: $\mathrm{AHI}$, apnea-hypopnea index; $\mathrm{BMI}$, body mass index; $\mathrm{SaO}_{2}$, oxygen saturation.

Patients were instructed to swallow and to close their mouths with maximal intercuspation and the lips in a relaxed position when they were without and with $\mathrm{OA}_{\mathrm{m}}$.

Anatomically, the pharyngeal airway is divided in nasopharyngeal, oropharyngeal, and hypopharyngeal. ${ }^{32}$ The cephalometric variables analysis of airway space used were mapped in -Fig. 2A (pre-treatment) and 2B (pretreatment) showing the mode of action of $\mathrm{OA}_{\mathrm{m}}$ used in the study to identify tongue, soft palate, and pharyngeal airway.

\section{Oral Appliance Therapy}

Impressions of the dental arches and face bow to construct the gnathostatic study model based on Camper plane were made, and the constructive bite was determined by using George Gauge ${ }^{\circledR}$ bite fork.

The initial protocol of $\mathrm{OA}_{\mathrm{m}}$ construction were with 65 to $75 \%$ maximum protrusion and a vertical opening of 3 to $4 \mathrm{~mm}$ between incisor edges. The efficacy of $\mathrm{OA}_{\mathrm{m}}$ was deter- mined by using additional PSG with $\mathrm{OA}_{\mathrm{m}}$ in situ after a minimum of 3 months.

\section{Questionnaires}

Subjective daytime sleepiness was evaluated by applying the Epworth sleepiness scale pre- and post-treatment, and a questionnaire to assess snoring, adherence, satisfaction, and safety of $\mathrm{OA}_{\mathrm{m}}$ usage to partners and to the patient follow-up. The adapted questionnaire ${ }^{29}$ consisted in following questions: Are you using $\mathrm{OA}_{\mathrm{m}}$ ? If yes, mark on a scale of 1 to 3 (where: $1=$ little, $2=$ medium and $3=$ a lot); Is your partner snoring with $\mathrm{OA}_{\mathrm{m}}$ ? If yes, mark on a scale of 1 to 3 (where: $1=$ little, $2=$ medium and $3=\mathrm{a}$ lot); and Are you totally satisfied with $\mathrm{OA}_{\mathrm{m}}$ ? Has $\mathrm{OA}_{\mathrm{m}}$ already broken?

\section{Success Criteria}

We evaluated the successful criteria of therapies with arousal index in addition to respiratory parameters, as $\mathrm{AHI}$ and $\mathrm{SaO}_{2}$, 


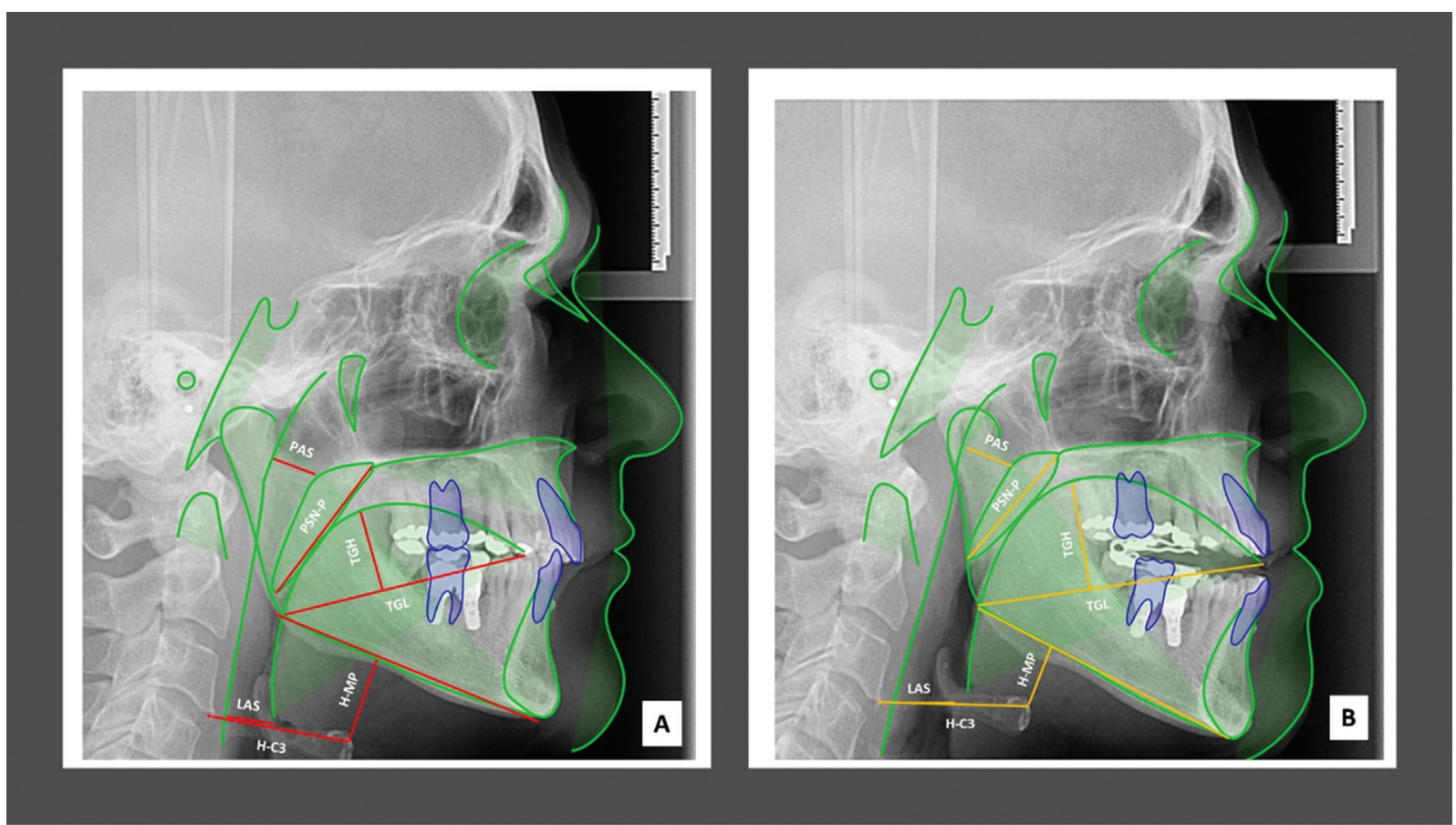

Fig. 2 The mode of action of oral appliance with mandibular advancement used are mapped in (A) (pre-treatment) and (B) (post-treatment) in of airway space to identify tongue, soft palate, and pharyngeal airway. Lines and plans used in cephalometric variables analysis: soft palate length; posterior air space; hyoid distance third cervical vertebrae; hyoid distance mandibular plane; tongue length; tongue height; and lower air space.

and daytime sleepiness. Despite the lack of consensus regarding the definition of a successful criteria, ${ }^{17}$ three successful criteria were adopted as a resolution of symptoms plus reduction of AHI: (1) success in AHI to <5/hour; (2) partial success at least $50 \%$ reduction in $\mathrm{AHI}$, but $\mathrm{AHI}>5 /$ hour; and (3) failure ongoing clinical symptoms and/or less than a $50 \%$ reduction in baseline AHI.

\section{Synthesis of Statistical Analysis}

Descriptive analysis based in contingency tables and correlated Chi-square tests and basic statistics was used to characterize the sample. Generalized linear mixed model for repeated measure and post hoc Tukey-Kramer test compares the variables pre- and post-treatment. Residual normality was accessed by the Shapiro-Wilk Test and Pearson correlation coefficients was used to test and quantify the association between polysomnographic and cephalometric data. All analysis was calculated by using the SAS System (SAS Institute Inc. The SAS System, release 9.4. SAS Institute Inc., Cary, North Carolina, United States, 2012) and in all statistical tests the level of significance was set in $5 \%$.

\section{Results}

The polysomnographic data comparison pre- and posttreatment with $\mathrm{OA}_{\mathrm{m}}$ (-Table 2 ) of sleep efficiency, $\mathrm{AHI}, \mathrm{AI}$, $\mathrm{SaO}_{2}$, and maximum heartbeats are the greatest significance $(p<0.0001)$. In the same way, the cephalometric data comparison regarding to the hyoid distance mandibular plane (H-MP) and upper pharyngeal space. Accompanied by other variables with significant results as the tongue length (TGL; $p=0.01)$, tongue height (TGH; $p=0.003)$, posterior air space (PAS; $p=0.002$ ), and lower air space (LAS; $p=0.01$ ).

The mean $\mathrm{OA}_{\mathrm{m}}$ adjustment pre- and post-treatment was conducted for $61.12 \%$ (15.44) to $100.70 \%$ (31.11) showing an important advancement $(p<0.0001)$ associated with the results.

Based on severity of $\mathrm{AHI}$, the pre- and post-treatment with $\mathrm{OA}_{\mathrm{m}}$ are represent in -Table 3 and -Fig. 3. The frequencies and percentages in line show a significant result in different levels of AHI ( $p=0.0001)$, with 17 total success (51.51\%), 9 partial success (27.27\%), and 7 unsuccess (21.21\%). In four patients with severe AHI, three reduce the AHI to mild and one to normal.

The improvement in respiratory parameters was confirmed not only by comparing the polysomnographic data $(p<0.0001)$ but also through direct associations ( - Table 4$)$ between $\mathrm{AHI}$ and both $\mathrm{AI}$ and maximum hazard ratio (HR), with correlation indices for AHI and AI $(r=0.87601$, $p=0.0001)$ and for AHI and the maximum HR $(r=0.51025$, $p=0.0001$ ), respectively; and an indirect association between $\mathrm{AHI}$ and $\mathrm{SaO}_{2}(\mathrm{r}=-0.54760 ; p=0.0008)$.

The pharyngeal space was expanded by considering the comparison and correlation of the cephalometric measurements (-Tables 2 and $\mathbf{4}$ ). The hyoid bone presented movement in the upward and forward - Table 5 , confirmed by the $\mathrm{H}-\mathrm{MP}(p<0.0001)$. The greater the PAS score, the greater the LAS $(r=0.88151 ; p=0.0001)$ achieved through OAT. Moreover, the correlation of the mandible-tongue relationship with the hyoid bone showed that the position of the H-MP directly correlated with the H-C3 $(p=0.0034)$ and with the $\operatorname{TGL}(p=0.0268)$, pre- and post-treatment. In addition, when 
Table 2 Cephalometric comparison of the mean (standard deviation) of the pre-and post-treatment variables with the mandibular oral appliance $(n=33)$

\begin{tabular}{|c|c|c|c|}
\hline \multirow[t]{2}{*}{ Characteristics } & \multicolumn{2}{|l|}{ Phase } & \multirow[t]{2}{*}{$p$-Value } \\
\hline & Pre-treatment & Post-treatment & \\
\hline \multicolumn{4}{|l|}{ Anthropometric data } \\
\hline BMI $\left(\mathrm{kg} / \mathrm{m}^{2}\right)$ & $27.63(3.24)$ & $27.77(3.24)$ & 0.4172 \\
\hline \multicolumn{4}{|l|}{ Polysomnographic data } \\
\hline Epworth sleepiness scale & $9.70(4.97)$ & $6.88(3.68)$ & 0.0004 \\
\hline Arousal index & $12.90(10.91)$ & $5.55(4.38)$ & $<0.0001$ \\
\hline $\mathrm{SaO}_{2}$ minute (\%) & $82.87(6.24)$ & $88.03(3.67)$ & $<0.0001$ \\
\hline Sleep efficiency & 76.09 (11.92) & $77.51(12.93)$ & $<0.0001$ \\
\hline Apnea & $8.57(10.94)$ & $1.56(3.09)$ & 0.0058 \\
\hline Hypopnea & $9.28(7.76)$ & $4.97(5.06)$ & 0.0318 \\
\hline $\mathrm{AHI}$ & $17.86(15.45)$ & $6.52(6.19)$ & $<0.0001$ \\
\hline Minimum heartbeat & $54.63(7.20)$ & $54.77(8.06)$ & 0.9655 \\
\hline Maximum heartbeat & $81.42(9.99)$ & $75.13(15.02)$ & 0.0140 \\
\hline Legs movements & $2.20(5.17)$ & $4.29(9.61)$ & 0.7172 \\
\hline \multicolumn{4}{|l|}{ Cephalometric data } \\
\hline Upper pharyngeal space & $15.90(3.69)$ & $19.58(3.77)$ & $<0.0001$ \\
\hline Soft palate length & $40.76(5.83)$ & $43.03(5.80)$ & 0.0206 \\
\hline Posterior air space & $12.71(4.21)$ & $14.99(3.94)$ & 0.0024 \\
\hline Hyoid distance mandibular plane & $26.51(7.44)$ & $19.28(5.77)$ & $<0.0001$ \\
\hline Tongue length & $77.75(9.23)$ & $79.93(9.32)$ & 0.0153 \\
\hline Tongue height & $27.84(5.20)$ & $30.75(5.41)$ & 0.0039 \\
\hline Lower air space & $11.99(4.63)$ & $13.60(4.60)$ & 0.0192 \\
\hline Hyoid distance third cervical vertebrae & $42.41(5.60)$ & $43.22(5.29)$ & 0.3052 \\
\hline \multicolumn{4}{|l|}{ Oral appliance therapy } \\
\hline $\mathrm{OA}_{\mathrm{m}}$ advancement $(\%)$ & $61.12(15.44)$ & $100.70(31.11)$ & $<.0001$ \\
\hline
\end{tabular}

Abbreviations: $\mathrm{BMI}$, body mass index; $\mathrm{OA}_{\mathrm{m}}$, oral appliance with mandibular advancement; $\mathrm{SaO}_{2}$ minimum, minimum oxygen saturation.

the mandible and tongue were protracted, there was a functional relationship between the hyoid bone and airway.

When cephalometric with polysomnographic variables were correlated, the H-MP is significantly with AHI $(\mathrm{r}=0.44025 ; \quad p=0.0003)$ and with AI $(\mathrm{r}=0.37683$; $p=0.0023)$.

In Epworth sleepiness scale questionnaire used for evaluating subjective parameters ( - Table 2 ), we observe a significant response in daytime sleepiness $(p=0.0004)$. Furthermore, we used a questionnaire to evaluate the adherence, usage, and security of $\mathrm{OA}_{\mathrm{m}}$ (-Table 6) showing a significant response $(p=0.001)$ for all questions except those related to snoring. Although 12 patients continued to present snoring, it was of low intensity $(p=0.0017)$.

Regarding adverse effects and symptoms from using the $\mathrm{OA}_{\mathrm{m}}, 12$ patients experienced mild and transitory adverse effects at the start of the treatment, which were resolved through massage in two patients, asymmetric adjustment in $\mathrm{OA}_{\mathrm{m}}$ to adjust the mandibular posture in eight cases, and specific occlusal adjustments of imbalanced occlusion in four cases.

\section{Discussion}

Here we provide the effectiveness of DIORS $\mathrm{OA}_{\mathrm{m}}$ on the outcome of OAT by expertise of the professional and the compliance of the patient. The positive effects of $\mathrm{OA}_{\mathrm{m}}$ that use Camper plane for disocclusion reference were demonstrated through comparison and correlation of objective data from polysomnography and cephalometry. In a sample of 33 patients of both genders, with primary snoring to severe OSA, we adopted the most impartial success criteria for apnea $(\mathrm{AHI}<5 \mathrm{ev} / \text { hour })^{17}$ resulting in $51.51 \%$ total successes to $27.27 \%$ partial success cases. Even so, the results are quite significant $(p<0.0001)$ for $\mathrm{AHI}, \mathrm{AI}, \mathrm{SaO}_{2}$ minimum, and for the maximum heartbeats ( $\mathbf{- T a b l e ~} \mathbf{2}$ ).

The $\mathrm{OA}_{\mathrm{m}}$ design, construction, and individualization influence the efficacy of OAT. ${ }^{3}$ We agree that one of the problems related to respiratory disorders is the skull structures relationship. ${ }^{11,13}$ In addition, the dental arches must be considered with to craniofacial structures. Unfortunately, most $\mathrm{OA}_{\mathrm{m}}$ are structured, using models dissociated from their relationship with craniometric structures and, 


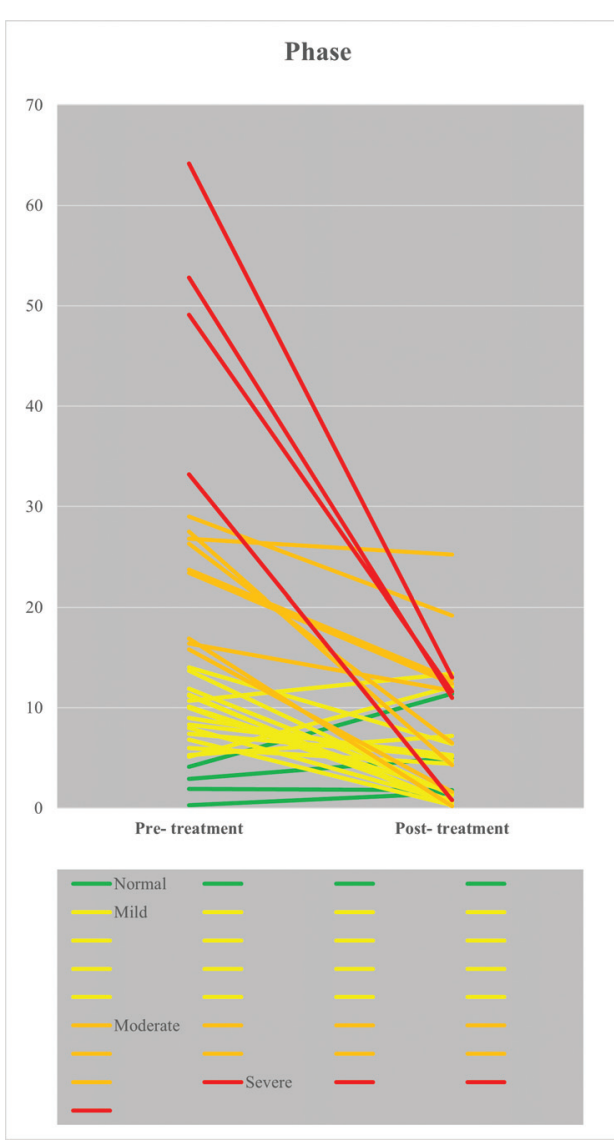

Fig. 3 Pre- and post-treatment of obstructive sleep apnea patients without and with oral appliance with mandibular advancement.

consequently, without respecting the muscles involved in mandibular protrusion movements. Here, we show an $\mathrm{OA}_{\mathrm{m}}$ that considers the morpho functional anatomy when seeking equilibrium for the stomatognathic system.

In polysomnographic variables, we observed the higher AHI the greater the arousal index and the greater the maximum heartbeats. In contrast, the higher the AHI, the lower the $\mathrm{SaO}_{2}$. In a study of various types of $\mathrm{OA}_{\mathrm{m}}{ }^{34}$ showing variable of success in the treatment of mild-to-moderate OSA to distinguish treatment responder from nonresponder patients, the authors observed that definitive device was effective in improving respiratory parameters as $\mathrm{AHI}$ as we observed in our data, but in the $\mathrm{SaO}_{2}$, they do not observed the same result that we had observed in our findings $(p<0.0001)$. When correlating heartbeats, both variables increase ( - Table 4 ). Based on these correlations together with comparison results, the effectiveness of OAT is confirmed in the upper airway permeability improvement. In addition, contributing to the $\mathrm{AHI}$ and $\mathrm{AI}$, it
Table 3 Chi-square likelihood ratio test with frequency and percentage in line of the apnea-hypopnea index classification and treatment phase $(n=33)$

\begin{tabular}{|l|l|l|}
\hline \multirow{2}{*}{ AHI classification } & \multicolumn{2}{|l|}{ Phase } \\
\cline { 2 - 3 } & Pre-treatment & Post-treatment \\
\hline Normal & $4(6.06)$ & $17(25.76)$ \\
\hline Mild & $16(24.24)$ & $14(21.21)$ \\
\hline Moderate & $9(13.64)$ & $2(3.03)$ \\
\hline Severe & $4(6.06)$ & \\
\hline
\end{tabular}

Abbreviations: AHI, apnea-hypopnea index.

Note: $p$-Value $=0.0001$.

also contributed to heartbeats improvement. ${ }^{8}$ All patients with severe OSA in this sample were treated, with three patients achieving a reduction of more than $50 \%$ in $\mathrm{AHI}$ and one patient reaching a normal level. In this sample, only two patients with moderate OSA did not respond to OAT. These patients presented clinically angle occlusal classification of Class I, large volume of tongue, flaccid soft palate, and cervical waist more than $40 \mathrm{~cm}$. In these cases of nonresponders patients to OAT, an alternative combined treatment with positive airway pressure ${ }^{10,34}$ or myofunctional therapy ${ }^{35}$ and BMI control ${ }^{36}$ can be prescribed to improve the AHI responses and patency of air space.

Based in cephalometric studies, ${ }^{14,30-33}$ here we also demonstrate the impact of $\mathrm{OA}_{\mathrm{m}}$ in upper airways with the uniquely designed $\mathrm{OA}_{\mathrm{m}}$ that advances the jaw and tongue simultaneously. Our findings reinforce former studies that showed that craniofacial morphology, which included bone and soft tissues, predisposed to OSAS, reducing the permeability of the upper airways.

Anatomically, the tongue maintains several relationships with the hyoid bone ${ }^{25}$ and, therefore, with the hyoid muscle. Several muscles of the tongue are inserted directly into the hyoid bone. Thus, the displacement of the tongue forward acts on the hyoid bone and vice versa, influencing the upward (cranial) displacement of the hyoid bone. The protrusion of the tongue or mandible, increasing the size of the airway cross-section in individuals with and without OSA, was already showed with the OAT. ${ }^{14,17,37}$ Furthermore, the significant increase in the upper airway permeability is probable related to $\mathrm{OA}_{\mathrm{m}}$ design. ${ }^{18}$ In our findings, we demonstrate that the $\mathrm{OA}_{\mathrm{m}}$ used in this study that use Camper plane as reference to disocclusion permits the jaw and the tongue simultaneous advancement and significantly increase the upper airway in OSA patients (-Fig. 2), confirming the

Table 4 Pearson's correlation index ( $p$-value) for quantifying the association between polysomnographic variables

\begin{tabular}{|c|c|c|c|c|c|c|}
\hline & \multicolumn{2}{|l|}{$\mathrm{AHI}$} & \multicolumn{2}{|c|}{$\mathrm{SaO}_{2}(\min ) \%$} & \multicolumn{2}{|c|}{ Minimum heartbeats } \\
\hline $\mathrm{SaO} 2$ (min)\% & -0.54760 & $(0.0001)$ & & & & \\
\hline Arousal index & 0.87601 & $(0.0001)$ & -0.41245 & $(0.0008)$ & & \\
\hline Maximum heartbeats & & & & & 0.51025 & $(0.0001)$ \\
\hline
\end{tabular}

Abbreviations: $\mathrm{AHI}$, apnea and hypopnea index; $\mathrm{SaO}_{2}$ (min), minimum oxygen saturation. 
Table 5 Persson's correlation index ( $p$-value) to quantify the association between cephalometric variables

\begin{tabular}{|l|l|l|l|l|l|l|l|l|}
\hline Variables & \multicolumn{2}{l|}{ TGH } & \multicolumn{2}{l|}{ TGL } & \multicolumn{2}{l|}{ LAS } & \multicolumn{2}{l|}{ H-C3 } \\
\hline PAS & 0.49702 & $0.0001^{\mathrm{b}}$ & 0.26976 & $0.0285^{\mathrm{a}}$ & 0.88151 & $0.0001^{\mathrm{b}}$ & 0.52311 & $0.0001^{\mathrm{b}}$ \\
\hline PNS-P & 0.47445 & $0.0001^{\mathrm{b}}$ & 0.63226 & $0.0001^{\mathrm{b}}$ & NS & & 0.38235 & $0.0015^{\mathrm{b}}$ \\
\hline TGH & \multicolumn{2}{|l|}{} & 0.65813 & $0.0001^{\mathrm{b}}$ & 0.30195 & $0.0137^{\mathrm{b}}$ & 0.43336 & $0.0003^{\mathrm{b}}$ \\
\hline H-MP & NS & 0.27259 & $0.0268^{\mathrm{a}}$ & NS & & 0.35549 & $0.0034^{\mathrm{b}}$ \\
\hline H-C3 & 0.43336 & $0.0003^{\mathrm{b}}$ & 0.55623 & $0.0001^{\mathrm{b}}$ & 0.47060 & $0.0001^{\mathrm{b}}$ &. & \\
\hline
\end{tabular}

Abbreviations: H-C3, hyoid distance third cervical vertebra; H-MP, hyoid distance mandibular plane; LAS, lower air space; NS, not significant; PAS, posterior air space; PNS-P, soft palate length; TGH, tongue height; TGL, tongue length.

${ }^{\mathrm{a}} \mathrm{p}<0.05$.

${ }^{b} p<0.01$.

Table 6 Frequency, percentage on the line, and Chi-square test ( $p$-value) of the answers obtained in the questionnaire applied to assess adherence, satisfaction and safety of oral appliance with mandibular advancement

\begin{tabular}{|c|c|c|c|}
\hline Questions & Frequency & $\%$ & $p$-Value \\
\hline \multicolumn{4}{|c|}{ Are you using $\mathrm{OA}_{\mathrm{m}}$ ? } \\
\hline No & 2 & 6.06 & \multirow[t]{2}{*}{$<0.0001$} \\
\hline Yes & 31 & 93.94 & \\
\hline \multicolumn{4}{|c|}{ Score use of 1 to 3} \\
\hline 1 & 1 & 3.23 & \multirow[t]{3}{*}{$<0.0001$} \\
\hline 2 & 3 & 9.68 & \\
\hline 3 & 27 & 87.1 & \\
\hline \multicolumn{4}{|c|}{ Are you using it every night? } \\
\hline No & 2 & 6.45 & \multirow[t]{2}{*}{$<0.0001$} \\
\hline Yes & 29 & 93.55 & \\
\hline \multicolumn{4}{|c|}{ Do you use $\mathrm{OA}_{\mathrm{m}}$ every night in week? } \\
\hline No & 3 & 9.67 & \multirow[t]{2}{*}{$<0.0001$} \\
\hline Yes & 28 & 90.32 & \\
\hline \multicolumn{4}{|c|}{ Is your partner snoring with $\mathrm{OA}_{\mathrm{m}}$ ? } \\
\hline No & 19 & 61.29 & \multirow[t]{2}{*}{0.2087} \\
\hline Yes & 12 & 38.71 & \\
\hline \multicolumn{4}{|c|}{ On what snoring score? } \\
\hline 0 & 18 & 60 & \multirow[t]{3}{*}{0.0017} \\
\hline 1 & 10 & 33.33 & \\
\hline 3 & 2 & 6.67 & \\
\hline \multicolumn{4}{|c|}{ Are you totally satisfied with $\mathrm{OA}_{\mathrm{m}}$ ? } \\
\hline No & 2 & 6.67 & \multirow[t]{2}{*}{$<0.0001$} \\
\hline Yes & 28 & 93.33 & \\
\hline \multicolumn{4}{|c|}{ Has $\mathrm{OA}_{\mathrm{m}}$ ever broken? } \\
\hline No & 26 & 83.87 & \multirow[t]{2}{*}{0.0002} \\
\hline Yes & 5 & 16.13 & \\
\hline
\end{tabular}

Abbreviation: $\mathrm{OA}_{\mathrm{m}}$, oral appliance with mandibular advancement. Note: Score $=0=$ none, $1=$ little, $2=$ medium and $3=$ much $/$ many.

effectiveness of this $\mathrm{OA}_{\mathrm{m}}$ (-Fig. 3). This affirmative is correlating to cephalometric and polysomnographic variables, demonstrating that the position of the hyoid bone is partly a factor that can interfere with airway permeability and sleep quality contributing to the significant reduction of these indexes $(p<0.0001)$.

In the subjective parameters, the Epworth sleepiness scale presents a significant result ( $p<0.0005)$. The questionnaire applied associated with adherence, satisfaction, symptoms, and safety of using $\mathrm{OA}_{\mathrm{m}}$ (-Table $\mathbf{6}$ ), we found significant results in terms of satisfaction and adherence $(p=0.0001)$, although there is still snoring presence, the results show an extremely low score, without disturbing the bed partner. Finally, safety of use shows that this $\mathrm{OA}_{\mathrm{m}}$ is safe to use $(p=0.0006)$.

The limitation of this study was the two-dimensional image used without provide volumetric measurements as OSA diagnostic tool, but this limitation was reduced with the follow-up polysomnography parameters. In addition, this sample was obtained in a private dental office that uses on protocol the cephalometry as a complementary diagnose tool, accessible to assist in the general assessment of soft tissues and bone configuration in the OAT. ${ }^{14,30-33}$ Even though, the statistical data obtained are encouraging, they need to be reinforced through further investigation about $\mathrm{OA}_{\mathrm{m}}$ design in larger studies to evaluate the clinical importance regard to the tongue, hyoid, mandibular posture, and the soft palate length in apneic patients pre- and post- treatment.

\section{Conclusion}

The OAT is an important determinant in the upper airway permeability in OSA treatment, reducing snoring and daytime sleepiness. In this pilot study, DIORS $\mathrm{OA}_{\mathrm{m}}$ as an uniquely designed device using Camper plane as a reference for disocclusion was effective in the control of OSA. Future studies should test and compare other $\mathrm{OA}_{\mathrm{m}}$ with DIORS $\mathrm{OA}_{\mathrm{m}}$ to confirm such important findings.

Funding

None.

Conflict of Interest

D.F.B. had a conflict of interest regarding the DIORS $\mathrm{OA}_{\mathrm{m}}$, which was created, registered, and patented by the author at National Institute of Industrial Property. Rest authors declare no conflict of interest. 


\section{References}

1 Drager LF, Genta PR, Pedrosa RP, et al. Characteristics and predictors of obstructive sleep apnea in patients with systemic hypertension. Am J Cardiol 2010;105(08):1135-1139

2 Kheirandish-Gozal L, Gozal D. Obstructive sleep apnea and inflammation: proof of concept based on two illustrative cytokines. Int J Mol Sci 2019;20(03):459

3 Senaratna CV, Perret JL, Lodge CJ, et al. Prevalence of obstructive sleep apnea in the general population: a systematic review. Sleep Med Rev 2017;34:70-81

4 Sateia MJ. International Classification of Sleep Disorders. 3rd edition. Chest; 2014

5 Flemons WW, Buysse D, Redline S, et al. Sleep-related breathing disorders in adults: recommendations for syndrome definition and measurement techniques in clinical research. The Report of an American Academy of Sleep Medicine Task Force. Sleep 1999; 22(05):667-689

6 Zancanella E, Haddad FM, Oliveira LAMP, et al; Associação Brasileira de Otorrinolaringologia e Cirurgia Cérvico-Facial Academia Brasileira de Neurologia Sociedade Brasileira de Cardiologia Sociedade Brasileira de Pediatria Sociedade Brasileira de Pneumologia e Tisiologia. Obstructive sleep apnea and primary snoring: diagnosis. Rev Bras Otorrinolaringol (Engl Ed) 2014;80(1, Suppl 1):S1-S16

7 Meira E Cruz M, Soca R, Kryger M. How much is too much after all? Primary snoring as a remaining unsolved issue. J Clin Sleep Med 2020;16(06):991

8 Ramar K, Dort LC, Katz SG, et al. Clinical practice guideline for the treatment of obstructive sleep apnea and snoring with oral appliance therapy: An update for 2015. J Clin Sleep Med 2015; 11(07):773-827

9 Alkhader M, Saadeh R. The knowledge of sleep medicine among dental interns in Northern Jordan. Eur J Dent 2021;15(02): 193-196

10 Premaraj TS, Stadiem J, Premaraj SA, Davies CR, Dennis M, Harrington JJ. Continuous positive airway pressure-mandibular advancement device combination therapy for moderate-to-severe obstructive sleep apnea: a preliminary study. Eur J Dent 2021;10.1055/s-0040-1719220. Doi: 10.1055/s-0040-1719220

11 Gungor AY, Turkkahraman H, Yilmaz HH, Yariktas M. Cephalometric comparison of obstructive sleep apnea patients and healthy controls. Eur J Dent 2013;7(01):48-54

12 Aly P, Mohsen C. Comparison of the accuracy of three-dimensional printed casts, digital, and conventional casts: an in vitro study. Eur J Dent 2020;14(02):189-193

13 Kurt G, Sisman C, Akin E, Akcam T. Cephalometric comparison of pharyngeal airway in snoring and non-snoring patients. Eur J Dent 2011;5(01):84-88

14 Sutherland K, Deane SA, Chan ASL, et al. Comparative effects of two oral appliances on upper airway structure in obstructive sleep apnea. Sleep (Basel) 2011;34(04):469-477

15 Lim J, Lasserson TJ, Fleetham J, Wright JJ. Oral appliances for obstructive sleep apnoea. Cochrane Database Syst Rev 2006;2006 (01):CD004435

16 Ngiam J, Balasubramaniam R, Darendeliler MA, Cheng AT, Waters $\mathrm{K}$, Sullivan CE. Clinical guidelines for oral appliance therapy in the treatment of snoring and obstructive sleep apnoea. Aust Dent J 2013;58(04):408-419

17 Ferguson KA, Cartwright R, Rogers R, Schmidt-Nowara W. Oral appliances for snoring and obstructive sleep apnea: a review. Sleep 2006;29(02):244-262

18 Liu C, Kang W, Zhang S, et al. Mandibular advancement devices prevent the adverse cardiac effects of obstructive sleep apneahypopnea syndrome (OSAHS). Sci Rep 2020;10(01):3394
19 Scherr SC, Dort LC, Almeida FR, et al. Definition of an effective oral appliance for the treatment of obstructive sleep apnea and snoring. J Dent Sleep Med 2014;1(01):39-50

20 Almeida FR, Vanderveken OM, Cistulli PA, et al. ORal appliance network on global effectiveness (ORANGE): start-up and design description. J Dent Sleep Med 2014;1(01):17-20

21 Marklund M. Update on oral appliance therapy for OSA. Curr Sleep Med Rep 2017;3(03):143-151

22 Marklund M, Braem MJA, Verbraecken J. Update on oral appliance therapy. Eur Respir Rev 2019;28(153):190083

23 Venugopalan SK, SatishBabu CL, Rani MS. Determination of the relative parallelism of occlusal plane to three ala-tragal lines in various skeletal malocclusions: a cephalometric study. Indian J Dent Res 2012;23(06):719-725

24 Bamagoos AA, Cistulli PA, Sutherland K, et al. Dose-dependent effects of mandibular advancement on upper airway collapsibility and muscle function in obstructive sleep apnea. Sleep (Basel) 2019;42(06):1-10

25 Bérzin F. Electromyographic analysis of the sternohyoid muscle and anterior belly of the digastric muscle in head and tongue movements. J Oral Rehabil 1995;22(11):825-829

26 Ahrens A, McGrath C, Hägg U. A systematic review of the efficacy of oral appliance design in the management of obstructive sleep apnoea. Eur J Orthod 2011;33(03):318-324

27 Haviv Y, Bachar G, Aframian DJ, Almoznino G, Michaeli E, Benoliel R. A 2-year mean follow-up of oral appliance therapy for severe obstructive sleep apnea: a cohort study. Oral Dis 2015;21(03): 386-392

28 Schwartz M, Acosta L, Hung YL, Padilla M, Enciso R. Effects of CPAP and mandibular advancement device treatment in obstructive sleep apnea patients: a systematic review and meta-analysis. Sleep Breath 2018;22(03):555-568

29 Barbosa DF, Giannasi LC, Ferreira LMDB, Cruz MME, Alves MC, Berzin F. A singular oral appliance to treat obstructive sleep apnea in CPAP non-adherent patients. Dental Press J Orthod 2020;25 (05):44-50

30 Chan ASL, Lee RWW, Cistulli PA. Dental appliance treatment for obstructive sleep apnea. Chest 2007;132(02):693-699

31 Guilleminault C, Riley R, Powell N. Obstructive sleep apnea and abnormal cephalometric measurements. Implications for treatment. Chest 1984;86(05):793-794

32 Lowe AA, Ono T, Ferguson KA, Pae EK, Ryan CF, Fleetham JA. Cephalometric comparisons of craniofacial and upper airway structure by skeletal subtype and gender in patients with obstructive sleep apnea. Am J Orthod Dentofacial Orthop 1996;110 (06):653-664

33 Cunha TCA, Guimarães TM, Schultz TCB, et al. Predictors of success for mandibular repositioning appliance in obstructive sleep apnea syndrome. Braz Oral Res 2017;31:e37

34 Segù M, Cosi A, Santagostini A, Scribante A. Efficacy of a trial oral appliance in OSAS management: a new protocol to recognize responder/nonresponder patients. Int J Dent 2021;2021:8811700

35 Mediano O, Romero-Peralta S, Resano P, et al. Obstructive sleep apnea: emerging treatments targeting the genioglossus muscle. J Clin Med 2019;8(10):1754. Doi: 10.3390/jcm8101754

36 Stavrou VT, Vavougios GD, Astara K, Siachpazidou DI, Papayianni E, Gourgoulianis KI. The 6-minute walk test and anthropometric characteristics as assessment tools in patients with obstructive sleep apnea syndrome. a preliminary report during the pandemic. J Pers Med 2021;11(06):563

37 Schwab RJ, Pasirstein M, Pierson R, et al. Identification of upper airway anatomic risk factors for obstructive sleep apnea with volumetric magnetic resonance imaging. Am J Respir Crit Care Med 2003;168(05):522-530 